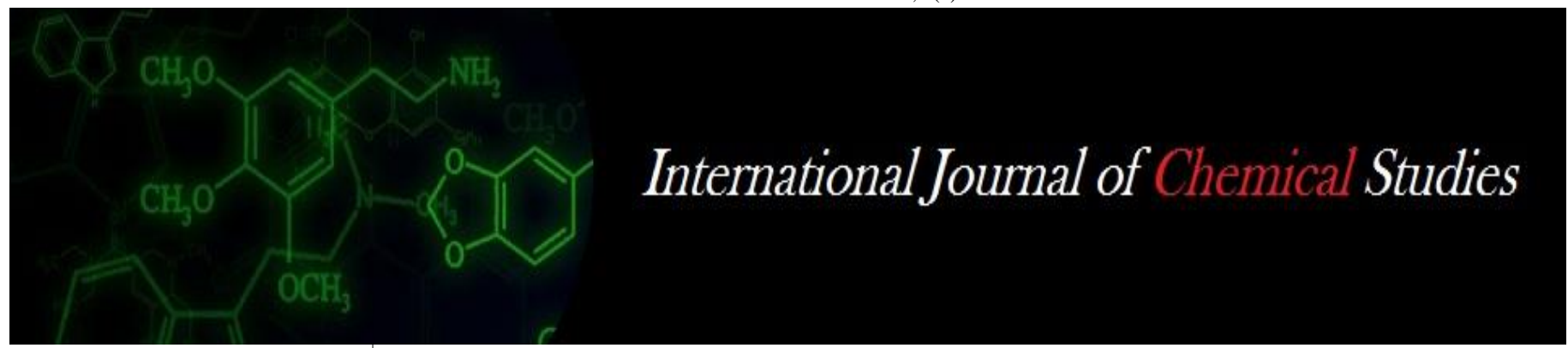

P-ISSN: 2349-8528

E-ISSN: 2321-4902

IJCS 2020; 8(1): 1781-1784

(C) 2020 IJCS

Received: 16-11-2019

Accepted: 18-12-2019

\section{Harkesh Saini}

Department of Plant Breeding

and Genetics, College of

Agriculture, S.K. Rajasthan

Agricultural University, Bikaner,

Rajasthan, India

\section{Sharma}

Department of Plant Breeding and Genetics, Professor,

Agriculture Research Station, S.

K. Rajasthan Agricultural

University, Bikaner, Rajasthan,

India

Lipendr Kumar Saini

Department of Plant Breeding

and Genetics, College of

Agriculture, S.K. Rajasthan

Agricultural University, Bikaner,

Rajasthan, India

Kanti Lal Solanki

Department of Plant Breeding

and Genetics, College of

Agriculture, S.K. Rajasthan

Agricultural University, Bikaner,

Rajasthan, India

Akash Gaurav Singh

Department of Plant Breeding

and Genetics, College of

Agriculture, S.K. Rajasthan

Agricultural University, Bikaner,

Rajasthan, India

Corresponding Author:

\section{Harkesh Saini}

Department of Plant Breeding

and Genetics, College of

Agriculture, S.K. Rajasthan

Agricultural University, Bikaner,

Rajasthan, India

\section{Genetic divergence analysis in groundnut (Arachis hypogaea $\mathrm{L}$.}

\author{
Harkesh Saini, MM Sharma, Lipendr Kumar Saini, Kanti Lal Solanki \\ and Akash Gaurav Singh
}

DOI: https://doi.org/10.22271/chemi.2020.v8.i1z.8523

\begin{abstract}
Genetic diversity among RILs of groundnut were estimated using Mahalanobis $\mathrm{D}^{2}$ statistic for seventeen characters. The analysis of variance revealed significant differences among the RILs for all characters. Based on Tocher's method, 149 RILs were grouped into fifteen clusters. Cluster II was the largest, holding 40 RILs followed by cluster I (34 RILs), cluster IV (14 RILs), cluster VI (14 RILs), VIII cluster (10 RILs), cluster V (7 RILs), cluster VII (6 RILs), cluster X (6 RILs), cluster IX (4 RILs), cluster XIII (4 RILs), cluster XI (3 RILs), cluster XIV (3 RILs), III cluster (2 RILs). Whereas cluster XII and XV were unique with only one RILs in each. This grouping indicated considerable diversity among the RILs. Cluster III had RILs with desirable characters like number of kernels per pod, 100-kernel weight, kernel yield per plant and biological yield per plant. Similarly, other clusters like VIII and were also possessed different character combinations. Intra-cluster distance was highest for cluster VI while inter-cluster distance between cluster III and cluster VII was maximum, indicating the existence of high variability within and between clusters.
\end{abstract}

Keywords: Groundnut, $D^{2}$ and genetic divergence

\section{Introduction}

Groundnut is one of the important oilseeds crop grown among? Countries of the world. It is native to South America and it belongs to the family 'Leguminosae'. It is a self-pollinated crop, allotetraploid with diploid chromosome number $2 n=40$. It has wide variety of uses viz., kernel directly used for table purposes or can be crushed for oil, vine with leaves as fodder and shell can be made to particleboard. Groundnut oil contains 46 and 32 percent of monounsaturated fatty acids (MUFA) and polyunsaturated fatty acids (PUFA), respectively.

This analysis provides the basis for grouping the germplasm collections into different homogenous groups and therefore, it is helpful in reducing the size of germplasm collection to be evaluated. The $\mathrm{D}^{2}$ statistic for multivariate analysis has been successfully used to select divergent genotypes in order to exploit heterosis and for bringing together higher frequency of desirable genes in the segregates. Thus, the knowledge of genetic variability and genetic divergence in combination with character association allows a breeder to select suitable and divergent genotypes for their use in breeding strategies and to formulate a suitable selection scheme.

\section{Materials and Methods}

The experimental material included single seed descent method derived 150 Recombinant Inbred Lines (RILs) of groundnut parental lines CHICO and ICGV 12473, which were procured from International Crops Research Institute for the Semi-Arid Tropics Patancheru, Hyderabad, India, through All India Coordinated Research Project on Groundnut, ARS Bikaner.

The experiment was conducted during Kharif 2016 in alpha lattice design (15 x 10) with a spacing of $30 \mathrm{~cm}$ between rows and $10 \mathrm{~cm}$ between plant to plant within the rows. The experiment material was sown on June 30, 2016 and one line (No. 49) germinated after 30 days and could not produced pods, therefore, could not be included in the study and the remaining 149 RILs were evaluated for traits related to yield and quality. The experiment was harvested on November 4, 2016. 
The observations were recorded on the basis of five randomly selected representative plants from each replication for ten characters viz., days to $50 \%$ flowering, days to maturity, number of branches per plant, number of pods per plant, pod yield per plant, number of kernels per pod, kernel yield per plant (g), 100-kernel weight (g), shelling percentage, biological yield per plant, harvest index, protein content, oil content and fatty acids.

The genetic diversity between genotypes was worked out using Mahalanobis D ${ }^{2}$ (1936) ${ }^{[6]}$ extended by Rao (1952) ${ }^{[7]}$. On the basis of $\mathrm{D}^{2}$ values the genotypes were grouped into clusters according to Tocher's method (Rao, 1952) ${ }^{\text {[7]. The }}$ method of Singh and Chaudhary (1985) [9] were used to calculate the intra and inter-cluster distances. All the statistical calculations were done using excel stat based computer software.

Results and Discussion: The 149 RILs of groundnut were grouped into fifteen clusters based on $\mathrm{D}^{2}$ value (Table 1). Among the clusters, cluster II contained maximum number of RILs (40) followed by cluster I with 34 RILs, cluster IV and VI with 14 RILs, VIII cluster with 10 RILs, cluster V with 7 RILs, cluster VII, X with 6 RILs, cluster IX, XIII with 4
RILs, XI, XIV cluster with 3 RILs, III cluster with 2 RILs, whereas cluster XII and XV were unique, since, each had only one RILs. This grouping indicated considerable diversity among the RILs.

The inter-cluster distance (Table 2) was larger than the intracluster distance which indicated that greater diversity is present among the genotypes of distant group (Zaman et al., 2010) ${ }^{[12]}$. The inter-cluster distance analysis shows that the maximum divergence was observed between cluster III and cluster VII (94.866). The inter-cluster distance between cluster III and cluster VII, followed by cluster III and cluster $\mathrm{XV}$, cluster I and cluster III, cluster III and cluster IV were relatively high as compared to other, so the genotypes in these clusters can be utilized for selection of parents for hybridization. Similar results were also suggested by Choudhary et al. (1998) ${ }^{[2]}$. Minimum inter-cluster distance was observed between cluster II and cluster VI (6.573). The highest intra-cluster distance was observed in cluster VI (28.682), followed by cluster V (25.962), cluster III (25.803) and cluster IX (23.882). The intra cluster distance was not present in cluster XII and XV as these clusters had only one RILs each.

Table 1: Distribution of one hundred forty-nine groundnut RILs into different clusters

\begin{tabular}{|c|c|c|}
\hline Cluster & Number of RILs & Composition of clusters \\
\hline I & 34 & $\begin{array}{c}\text { RILs No. } 1,2,10,11,12,14,15,17,18,19,20,21,24,27,33,34,54,56,72,73,78,79,84,92,96,100, \\
102,105,106,110,118,123,128,137\end{array}$ \\
\hline II & 40 & $\begin{array}{c}\text { RILs No. } 3,7,13,25,29,30,31,32,36,44,47,48,50,51,58,63,68,69,71,75,85,88,98,99,104 \\
107,111,112,115,124,129,133,135,138,139,140,145,146,147,148\end{array}$ \\
\hline III & 2 & RILs No. 4,28 \\
\hline IV & 14 & RILs No. 5,38,39,41,45,46,55,62,64,65,86,95,108,120 \\
\hline $\mathrm{V}$ & 7 & RILs No. $6,23,40,77,113,117,136$ \\
\hline VI & 14 & RILs No. 8,16,22,26,35,57,76,83,90,94,114,125,127,141 \\
\hline VII & 6 & RILs No. 9, 60,61,81, 89,103 \\
\hline VIII & 10 & RILs No. 37,42,43,59,70,74,97,109,116,142 \\
\hline IX & 4 & RILs No. 52, 53, 93,101 \\
\hline $\mathrm{X}$ & 6 & RILs No. 66, 121,122,130,131,134 \\
\hline XI & 3 & RILs No. $67,126,144$ \\
\hline XII & 1 & RILs No. 80 \\
\hline XIII & 4 & RILs No. 82, 87,143,149 \\
\hline XIV & 3 & RILs No. 91,132,150 \\
\hline $\mathrm{XV}$ & 1 & RILs No. 119 \\
\hline
\end{tabular}

Table 2: Average intra and inter cluster distances $\left(D=\sqrt{ } D^{2}\right)$ in groundnut RILs

\begin{tabular}{|c|c|c|c|c|c|c|c|c|c|c|c|c|c|c|c|}
\hline Clusters & I & II & III & IV & V & VI & VII & VIII & IX & X & XI & XII & XIII & XIV & XV \\
\hline I & 23.206 & 24.685 & 80.368 & 27.918 & 31.156 & 21.218 & 22.244 & 30.392 & 50.224 & 44.229 & 42.262 & 58.401 & 25.408 & 50.919 & 24.148 \\
\hline II & & 21.300 & 64.912 & 18.144 & 12.092 & 6.573 & 31.959 & 10.248 & 27.855 & 24.893 & 20.930 & 36.841 & 10.371 & 33.606 & 18.297 \\
\hline III & & & 25.803 & 77.072 & 55.513 & 64.669 & 94.866 & 61.720 & 44.904 & 49.950 & 56.498 & 56.230 & 69.350 & 42.636 & 80.763 \\
\hline IV & & & & 18.840 & 23.257 & 19.662 & 24.216 & 23.424 & 37.582 & 29.959 & 33.662 & 42.408 & 24.295 & 40.021 & 9.236 \\
\hline V & & & & & 25.962 & 11.994 & 40.653 & 12.932 & 20.627 & 16.398 & 21.023 & 35.311 & 20.798 & 23.729 & 26.308 \\
\hline VI & & & & & & 28.682 & 31.088 & 10.858 & 29.913 & 26.508 & 23.288 & 41.296 & 13.985 & 34.596 & 19.943 \\
\hline VII & & & & & & & 16.985 & 36.500 & 57.645 & 51.800 & 49.061 & 62.428 & 31.972 & 60.911 & 19.244 \\
\hline VIII & & & & & & & 21.291 & 25.193 & 25.865 & 19.642 & 37.361 & 14.788 & 33.871 & 24.097 \\
\hline IX & & & & & & & & & 23.882 & 16.171 & 20.162 & 27.142 & 34.340 & 22.404 & 42.163 \\
\hline X & & & & & & & & & & 18.364 & 25.086 & 26.151 & 33.300 & 13.527 & 35.575 \\
\hline XI & & & & & & & & & & & 20.338 & 30.456 & 24.095 & 32.985 & 35.307 \\
\hline XII & & & & & & & & & & & 0.000 & 40.125 & 30.817 & 46.197 \\
\hline XIII & & & & & & & & & & & & & 19.710 & 40.516 & 21.068 \\
\hline XIV & & & & & & & & & & & & & & 17.763 & 45.029 \\
\hline XV & & & & & & & & & & & & & & 0.000 \\
\hline
\end{tabular}


Table 3: Cluster means for seventeen characters in groundnut

\begin{tabular}{|c|c|c|c|c|c|c|c|c|c|c|c|c|c|c|c|}
\hline Characters & I & II & III & IV & $\mathbf{V}$ & VI & VII & VIII & IX & $\mathbf{X}$ & $\mathbf{X I}$ & XII & XIII & XIV & XV \\
\hline Days to $50 \%$ flowering & 33.59 & 33.82 & 34.47 & 33.86 & 34.56 & 33.22 & 33.47 & 33.39 & 33.56 & 36.07 & 35.73 & 33.55 & 33.59 & 33.78 & 37.17 \\
\hline Days to maturity & 127.23 & 127.28 & 127.24 & 127.16 & 127.28 & 127.35 & 127.29 & 127.04 & 127.15 & 127.17 & 127.29 & 127.32 & 127.08 & 127.09 & 127.91 \\
\hline Number of branches per plant & 7.18 & 7.52 & 7.47 & \begin{tabular}{|l|l|}
7.3 \\
\end{tabular} & 8.17 & 7.32 & 7.4 & 7.58 & \begin{tabular}{|l|}
7.31 \\
\end{tabular} & 7.58 & 7.3 & 8.38 & 7.44 & 7.65 & 7.27 \\
\hline Number of pods pe & 17.74 & 22.28 & 24 & 17.08 & 21.1 & 20.22 & 19.04 & 25.08 & 24.97 & 15.69 & 17.77 & 17.72 & 25.98 & 15 & 19.22 \\
\hline Pod & 21.41 & 23.43 & 20.6 & 14.59 & 21.74 & 24.21 & 8.27 & 26.95 & 21.87 & 14.39 & 32.19 & 13.63 & 28.1 & 15.59 & 18.35 \\
\hline Shell & 64.63 & 62.22 & 66.3 & 62.3 & 64.62 & 64.96 & 63.09 & 62.69 & \begin{tabular}{|l|}
69.21 \\
\end{tabular} & 64 & 66.28 & 51.17 & 56.87 & 58.41 & 58.86 \\
\hline Number $\mathrm{c}$ & 1.64 & 1.68 & 1.8 & 1.49 & 1.66 & 1.62 & 1.67 & 1.63 & 1.59 & 1.58 & 1.53 & 1.68 & 1.51 & 1.49 & 1.53 \\
\hline Kern & 12.85 & 13.66 & 24.88 & 9.19 & 13.12 & 14.44 & 10.61 & 15.35 & 13.74 & 8.95 & 18.23 & 8.92 & 15.43 & 8.11 & 10.97 \\
\hline 1001 & 61.94 & \begin{tabular}{|l|}
49.79 \\
\end{tabular} & 77.14 & 41.57 & 54.74 & 53.48 & 43.37 & 48.24 & 47.43 & 51.16 & 43.66 & 36.88 & 49.18 & 59.71 & 42.57 \\
\hline Bio & 62.84 & 83.07 & 140.52 & 75.41 & 91.65 & 81.52 & 53.41 & 87.54 & 109.49 & 103.42 & 98.2 & 111.84 & 79.32 & 110.44 & 69.9 \\
\hline Harv & 22.89 & 18.64 & 20.66 & \begin{tabular}{|l|}
11.59 \\
\end{tabular} & 14.63 & \begin{tabular}{|l|}
19.73 \\
\end{tabular} & 19.39 & 21.32 & 15.2 & 12.06 & 21.06 & 22.31 & 21.84 & 8.23 & 13.51 \\
\hline Prote & 24.66 & 24.98 & 24.96 & 25.48 & 23.91 & 24.99 & 23.34 & 24.49 & 24.83 & 24.88 & 23.09 & 23.64 & 25.27 & 24.73 & 24.78 \\
\hline Oil & 49.71 & 49.58 & 49.24 & \begin{tabular}{|l|}
48.34 \\
\end{tabular} & 49.6 & 49.24 & 51.56 & 49.62 & 48.54 & 49.1 & 51.3 & 48.6 & 51.56 & 51.26 & 47.36 \\
\hline Palm & 11.96 & 12.07 & 11.76 & 11.47 & 11.97 & 11.98 & 11.38 & 11.08 & \begin{tabular}{|l|l|}
12.29 \\
\end{tabular} & 12.07 & 12.79 & 13.06 & 12.42 & 11.76 & 11.45 \\
\hline & 2.75 & \begin{tabular}{|l|}
2.85 \\
\end{tabular} & \begin{tabular}{|l|}
2.98 \\
\end{tabular} & \begin{tabular}{|l|}
2.7 \\
\end{tabular} & 2.71 & \begin{tabular}{|l|}
2.7 \\
\end{tabular} & 3.06 & \begin{tabular}{|l|l|}
2.71 \\
\end{tabular} & \begin{tabular}{|l|}
2.7 \\
\end{tabular} & 2.55 & 2.82 & 2.62 & 3.46 & \begin{tabular}{|l|}
3.13 \\
\end{tabular} & 2.46 \\
\hline & 34.08 & 32.7 & 34.59 & 36.39 & 35.57 & 35.29 & 38.2 & 38.38 & 32.95 & 34.36 & 29.09 & 25.7 & 30.69 & 34.93 & 35.68 \\
\hline Linoleic acid (\%) & 45.26 & 46.46 & 44.56 & 42.96 & 43.1 & 44.06 & 42.54 & 42.18 & \begin{tabular}{|l|l|}
45.63 \\
\end{tabular} & 45.23 & 49.21 & 52.31 & 49.1 & \begin{tabular}{|l|}
44.06 \\
\end{tabular} & 44.71 \\
\hline
\end{tabular}

The Cluster mean value (Table 3) for different clusters indicated that cluster III recorded the highest cluster mean for number of kernels per pod, 100-kernel weight, kernel yield per plant (g) and biological yield per plant. Cluster XIII was the best source for number of pods per plant, pod yield per plant, oil content and stearic acid. Cluster XV was the best source for days to $50 \%$ flowering and days to maturity.

Contribution of character towards divergence (Table 4) was observed maximum in harvest index (15.15). Anuradha (1995) [1] also recorded the similar results in groundnut. However, the differences were clearer for kernel yield per plant followed by pod yield per plant, biological yield per plant, 100-kernel weight and number of pods per plant. The present findings are in conformity with those reported earlier in groundnut (Dashora and Nagda (2004) ${ }^{[3]}$; Sonone and Thaware (2009) ${ }^{[10]}$.

Table 4: Contribution of various characters to divergence

\begin{tabular}{|c|c|c|}
\hline S. No. & Characters & Contribution (\%) \\
\hline 1 & Days to 50\% flowering & 1.18 \\
\hline 2 & Days to maturity & 0.06 \\
\hline 3 & Number of branches per plant & 2.78 \\
\hline 4 & Number of pods per plant (g) & 8.81 \\
\hline 5 & Pod yield per plant (g) & 13.04 \\
\hline 6 & Shelling percentage & 3.77 \\
\hline 7 & Number of kernels per pod & 3.27 \\
\hline 8 & Kernel yield per plant(g) & 13.26 \\
\hline 9 & $100-$ kernel weight $(\mathrm{g})$ & 10.91 \\
\hline 10 & Biological yield per plant (g) & 11.7 \\
\hline 11 & Harvest index (\%) & 15.15 \\
\hline 12 & Protein content (\%) & 1.75 \\
\hline 13 & Oil content (\%) & 1.17 \\
\hline 14 & Palmitic acid (\%) & 2.16 \\
\hline 15 & Stearic acid (\%) & 3.76 \\
\hline 16 & Oleic acid (\%) & 4.37 \\
\hline 17 & Linoleic acid (\%) & 2.85 \\
\hline
\end{tabular}

The greatest contribution of 100-kernel weight towards divergence was also earlier reported by Golakia and Makne (1991) ${ }^{[4]}$, Reddy and Reddy (1993) ${ }^{[8]}$, Lakshmidevamma et al. (2006) ${ }^{[5]}$ and Venkatesh et al. (2015) ${ }^{[11]}$. It has been suggested that the character with maximum contribution towards divergence should be given importance for undergoing hybridization programme. Considering the cluster distances and cluster means in the present investigation, emphasis should be given to genotypes belonging cluster III, VIII, XV, XIII and VII for exploitation as parents in hybridization programme.

\section{Reference}

1. Anuradha V. Studies on genetic diversity in thirty genotypes of groundnut (Arachis hypogaea L.) M.Sc thesis, Andhra Pradesh Agricultural University, Hyderabad, 1995.
2. Choudhary MAZ, Mia MFU, Afzal MA, Ali MM. Comparative study of D2 and metroglyph analysis in groundnut. (Arachis hypogaea L.), Thailand J Agric. Sci. 1998; 31(3):436-443.

3. Dashora A, Nagda AK. Divergence analysis in groundnut (Arachis hypogea L.), In: The national symposium on enhancing productivity of groundnut for sustaining food and nutritional security held at NRCG Junagadh during October 11-12, 2004.

4. Golakia PR, Makne VG. Journal of Maharashtra Agri. Univ. 1991; 16(3):337-339.

5. Lakshmidevamma TN, Byregowda M, Mahadeva $\mathrm{P}$, Lakshmi G. Genetic divergence for yield and its component traits in groundnut germplasm. Indian J. of Plant Genet. Resour. 2006; 19(1):77-79.

6. Mahalanobis PC. A statistical study at Chinese head measurement. J Asiatic Soc. Bengal. 1936; 25:301-77. 
7. Rao CR. Advanced statistical methods in biometrical Research. End. I. John Wiley and Sons, New York, 1952.

8. Reddy KHP, Reddy KR. Genetic divergence in groundnut (Arachis hypogaea L.), Annual Agric. Res. 1993; 14(1):9-14.

9. Singh RK, Choudhar BD. Biometrical methods in quantitative genetics analysis. Kalyani Publisher, Ludhiana, 1985.

10. Sonone NG, Thaware BL. Analysis of genetic diversity for pod yield and other characters in groundnut (Arachis hypogaea L.), Green Farming. 2009; 2(11):742-744.

11. Venkatesh KA, Prasanna R, Srinivas T, Umamaheswari P. Assessment of genetic diversity for kernel yield and quantitative traits in drought tolerant groundnut genotypes. Electronic Journal of Plant Breeding, ISSN 0975-928 X, 29-36, 2015.

12. Zaman MA, Tuhina-Khatun M, Bhuiyan MH, Moniruzzamn M, Yousuf MN. Genetic divergence in Groundnut (Arachis hypogaea L.), Bangladesh J Pl. Breed. Genet. 2010; 23(1):45-49. 